\title{
The low fertility of repeat-breeder cows during summer heat stress is related to a low oocyte competence to develop into blastocysts
}

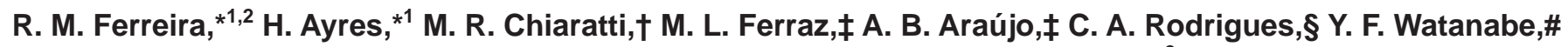 \\ A. A. Vireque,\# D. C. Joaquim,\# L. C. Smith, || F. V. Meirelles, $†$ and P. S. Baruselli ${ }^{2}$ \\ *Departamento de Reprodução Animal da Faculdade de Medicina Veterinária e Zootecnia da Universidade de São Paulo, São Paulo, SP, \\ Brazil 05508-000 \\ †Departamento de Ciências Básicas da Faculdade de Zootecnia e Engenharia de Alimentos da Universidade de São Paulo, Pirassununga, \\ SP, Brazil 13635-900 \\ ¥Vida Reprodutiva Consultoria, Cravinhos, SP, Brazil 14140-000 \\ §Clínica Veterinária SAMVET de São Carlos Ltda, São Carlos, SP, Brazil 13570-390 \\ \#VITROGEN Pesquisa e Desenvolvimento em Biotecnologia da Reprodução S/C Ltda, Cravinhos, SP, Brazil 14140-000 \\ \|Centre de Recherche em Reproduction Animale, Faculté de Médecine Vétérinarie, Université de Montréal, St. Hyacinthe, Québec, \\ Canada J2S 7C6
}

\begin{abstract}
It was hypothesized the lower fertility of repeat-breeder (RB) Holstein cows is associated with oocyte quality and this negative effect is enhanced during summer heat stress (HS). During the summer and the winter, heifers ( $\mathrm{H} ; \mathrm{n}=36$ and 34 , respectively), peak-lactation (PL; $\mathrm{n}=37$ and 32 , respectively), and $\mathrm{RB}(\mathrm{n}=36$ and 31 , respectively) Holstein cows were subjected to ovum retrieval to assess oocyte recovery, in vitro embryonic developmental rates, and blastocyst quality [terminal deoxynucleotidyl transferase-mediated dUTP nick end labeling (TUNEL)-positive cells and total cell number]. The environmental temperature and humidity, respiration rate, and cutaneous and rectal temperatures were recorded in both seasons. The summer HS increased the respiration rate and the rectal temperature of $\mathrm{PL}$ and $\mathrm{RB}$ cows, and increased the cutaneous temperature and lowered the in vitro embryo production of Holstein cows and heifers. Although cleavage rate was similar among groups $[\mathrm{H}=51.7 \% \pm 4.5(\mathrm{n}=375), \mathrm{PL}=$ $37.9 \% \pm 5.1(\mathrm{n}=390), \mathrm{RB}=41.9 \% \pm 4.5(\mathrm{n}=666)]$, blastocyst rate was compromised by HS, especially in $\mathrm{RB}$ cows $[\mathrm{H}=30.3 \% \pm 4.8(\mathrm{n}=244)$ vs. $23.3 \% \pm 6.4$ $(\mathrm{n}=150), \mathrm{PL}=22.0 \% \pm 4.7(\mathrm{n}=191)$ vs. $14.6 \% \pm$ $7.6(\mathrm{n}=103), \mathrm{RB}=22.5 \% \pm 5.4(\mathrm{n}=413)$ vs. $7.9 \%$ $\pm 4.3(\mathrm{n}=177)]$. Moreover, the fragmentation rate of RB blastocysts was enhanced during the summer, compared with winter $[4.9 \% \pm 0.7(\mathrm{n}=14)$ vs. $2.2 \%$ $\pm 0.2(\mathrm{n}=78)]$ and other groups $[\mathrm{H}=2.5 \% \pm 0.7(\mathrm{n}$ $=13)$, and $\mathrm{PL}=2.7 \% \pm 0.6(\mathrm{n}=14)]$ suggesting that
\end{abstract}

Received October 6, 2010

Accepted January 25, 2011.

${ }^{1} \mathrm{Co}$-first authors.

${ }^{2}$ Corresponding authors: robertinhavet@yahoo.com.br and barusell@ usp.br the association of RB fertility problems and summer HS may potentially impair oocyte quality. Our findings provide evidence of a greater sensitivity of RB oocytes to summer HS.

Key words: heat stress, oocyte quality, repeat-breeder cow, in vitro embryo production

\section{INTRODUCTION}

Repeat-breeder (RB) cows are commonly referred to as subfertile animals without any anatomic or infectious abnormality that do not become pregnant until the third or subsequent breeding or remain infertile after numerous services. The RB cows are characterized by low fertilization rates (Graden et al., 1968) and early embryonic loss (Gustafsson and Larsson, 1985), thereby decreasing overall conception rates (Ferreira et al., 2010b; Yusuf et al., 2010). Yet, gestational loss (30 to $60 \mathrm{~d}$ of pregnancy) between $\mathrm{RB}$ and non-RB cows is similar and transfer of non-RB donated embryos into $\mathrm{RB}$ surrogates increased RB pregnancy rate, indicating that the lower conception rate of RB cows was determined earlier in development (Ferreira et al., 2010b). Also, it has been suggested that the oocytes themselves are of inferior quality in RB (Gustafsson and Emanuelsson, 2002). Many aspects of the RB phenotype remain unknown (for instance, what season of the year that is most critical). According to a recent report (Yusuf et al., 2010), the incidence of RB was $14 \%$ in 9 commercial herds.

The reproductive performance of Holstein cows is compromised by heat stress (HS) and can be improved using embryo transfer (Ambrose et al., 1999; Baruselli et al., 2010). The decreased fertility associated with summer HS is a multifactorial problem in which hyperthermia affects cellular function in various tissues of the female reproductive tract (Wolfenson et al., 2000; 
Hansen et al., 2001). For instance, summer HS compromised ovarian follicular dynamics (Badinga et al., 1993), and the ability of the dominant follicle to exert dominance (Wolfenson et al., 1995). In addition, HS induced follicular codominance (Sartori et al., 2004; de S. Torres-Júnior et al., 2008) and decreased estrous cycle length, and the oocyte's competence to develop into a blastocyst. Oocytes harvested from Holstein cows during summer show decreased ability to develop to the blastocyst stage after in vitro fertilization when compared with oocytes harvested during winter (Rocha et al., 1998; Al-Katanani et al., 2002). Moreover, exposure of Holstein heifers to HS between the onset of estrus and insemination increased the proportion of abnormal and developmentally retarded embryos as compared with heifers maintained at thermoneutrality (Putney et al., 1989). These studies highlight the detrimental effect of HS on oocyte competence, from early stages of folliculogenesis, leading to a carryover effect on ovulated oocytes of low quality (Roth et al., 2001, de S. Torres-Júnior et al., 2008).

Because RB cows have lower conception rates during the summer than winter (Rodrigues et al., 2007), it is reasonable to hypothesize that the lower fertility of $\mathrm{RB}$ Holstein cows is associated with a decrease in oocyte competence due to summer HS. A previous study provided evidence of compromised quality in oocytes retrieved from RB heifers, as judged by their appearance at retrieval and their decreased ability to advance on the cytoplasmic spatial reorganization of mitochondria and cortical granules after in vitro maturation (Båge et al., 2003). These factors can indirectly explain the low oocyte quality and represent a contributing factor to subfertility that defines the RB syndrome in RB heifers. Hence, the aim was to address the hypothesis that the lower fertility of RB Holstein cows is associated with oocyte quality and that this negative effect is enhanced during summer.

\section{MATERIALS AND METHODS}

\section{Environmental and Physiological Measurements}

To identify the coolest and warmest periods of the year, and determine the months when the experiment would be conducted, a retrospective analysis of the environmental temperatures and humidity of the last 8 yr (Figure 1; January 2001 to January 2009) was done on 2 farms. Data were collected from each farm's weather station daily. The experiment was carried out in the second half of each season (winter and summer) to ensure at least $1 \mathrm{mo}$ of exposure to the desired environmental condition before the beginning of the trial. During the periods selected, the environmental
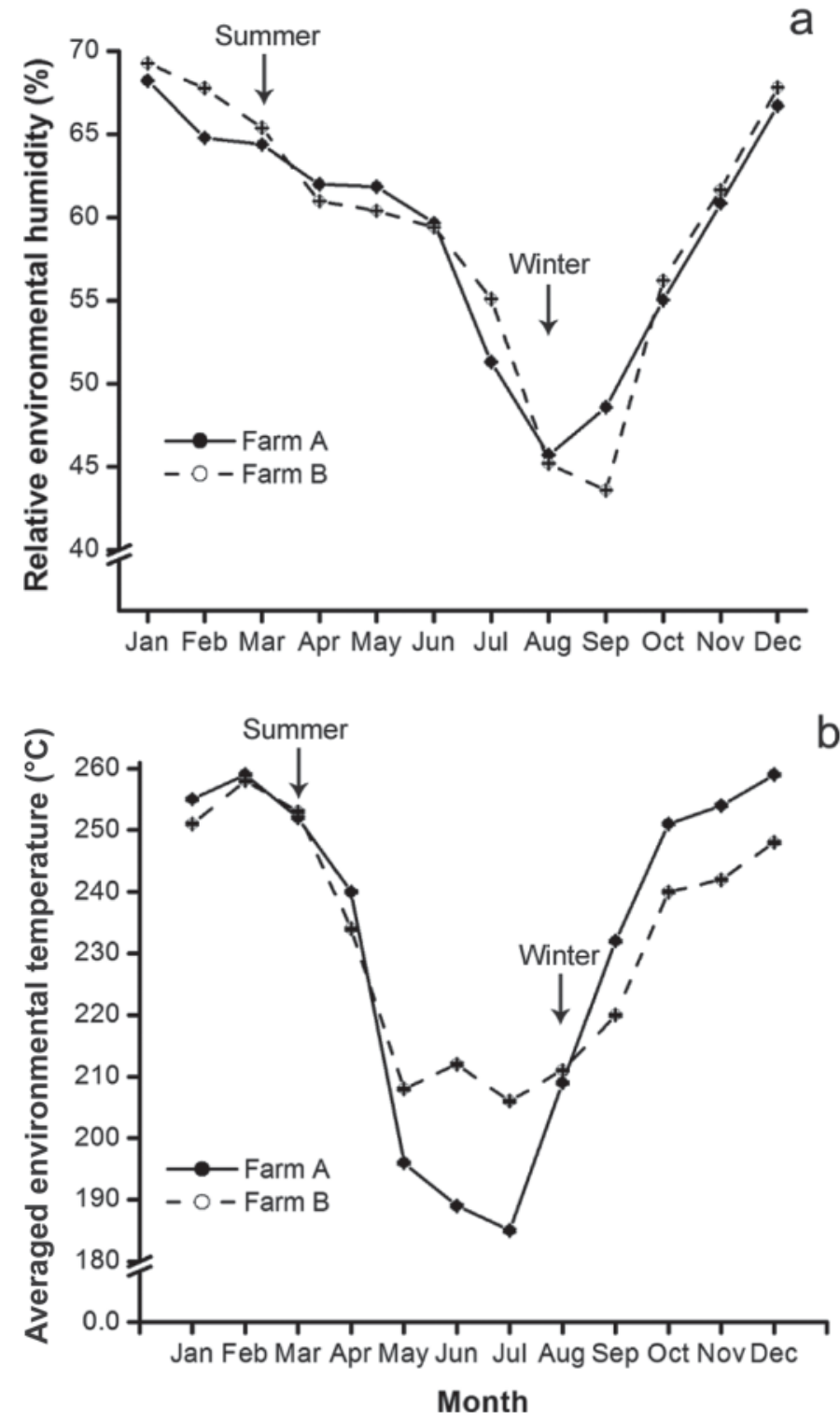

Figure 1. Monthly environmental humidity (a) and averaged environmental temperature (b) measured from weather stations of 2 dairy farms during an 8-yr period (2001 to 2009). Arrows indicate months chosen as the experimental summer (high humidity and temperature) and winter (low humidity and temperature).

temperature and humidity were recorded daily from the farm weather stations. Respiration rate and rectal and cutaneous temperature were recorded at the beginning of each protocol for synchronization of follicular wave emergence (d 0).

\section{Farm and Animals}

The present study was approved by the Bioethics Commission of the School of Veterinary Medicine and Zootechny of the University of São Paulo (protocol number 1571/2008), which complies with the ethical 
principles in animal research. The experiment was conducted in 2 commercial dairy farms located in São Paulo state in southeast Brazil: dairy A, the city of Descalvado $\left(21^{\circ} 54^{\prime} 14^{\prime \prime} \mathrm{S} 47^{\circ} 37^{\prime} 10^{\prime \prime} \mathrm{W}\right)$, and dairy B, the city of São Pedro $\left(22^{\circ} 32^{\prime} 55^{\prime \prime}\right.$ S $47^{\circ} 54^{\prime} 50^{\prime \prime}$ W) during the warm (March; summer) versus cool (August; winter) periods of 2009. Herds were composed of 1,800 and 400 lactating Holstein cows, producing $30.1 \pm 0.3$ and $34.2 \pm 0.2 \mathrm{~kg}$ of milk per day, in farms A and B, respectively. Holstein (Bos taurus) cattle of 3 different groups [heifers $(\mathbf{H}$; farm $\mathrm{A}, \mathrm{n}=52$ and farm $\mathrm{B}, \mathrm{n}=$ 18), peak-lactation cows ( $\mathbf{P L}$; farm $\mathrm{A}, \mathrm{n}=50$ and farm $\mathrm{B}, \mathrm{n}=19$ ), and $\mathrm{RB}$ cows (farm $\mathrm{A}, \mathrm{n}=48$ and farm $\mathrm{B}, \mathrm{n}=19)$ ] were used in this experiment. Heifers were $16.8 \pm 0.3 \mathrm{mo}( \pm \mathrm{SEM})$ old (farm $\mathrm{A}=17.2 \pm 0.4$ and farm $\mathrm{B}=15.5 \pm 0.5$ ), cycling, and had never been inseminated; RB were normal cycling lactating cows that had been inseminated several times (range from 4 to 13 services) without becoming pregnant and with no anatomic or infectious abnormality (checked by ultrasonography by a veterinarian); and PL were normal cycling cows raging from 46 to 171 DIM. The PL and $\mathrm{RB}$ cows were housed in freestalls with an adjacent pasture, but $\mathrm{H}$ were kept on pasture with free access to water. The PL and RB cows were $110.4 \pm 3.8$ and $425.3 \pm 17.5$ DIM $(P<0.0001$; Table S1, available online at http://www.journalofdairyscience.org/), had a weekly milk production of $34.3 \pm 0.7$ and $23.2 \pm 0.9$ $\mathrm{kg}(P<0.0001 ;$ Table S1), had $0.7 \pm 0.1$ and $7.1 \pm$ 0.3 previous inseminations $(P<0.0001$; Table S1), and were on lactation number $2.3 \pm 0.1$ and $2.0 \pm 0.2(P$ $=0.15$; Table S1), respectively. Animals were classified using a 1 (very thin) to 5 (very fat) point scale, with a difference of 0.25 points from one class to the next (Edmonson et al., 1989). The BCS was $3.15 \pm 0.2$ for $\mathrm{H}$, and not different from $3.13 \pm 0.4$ for RB cows and both were greater than the $2.77 \pm 0.3$ for PL cows $(P$ $<0.0001$; Table S1).

Cows were milked 3 times daily at approximately 8-h intervals. All animals were fed a TMR formulated to meet or exceed the minimum nutritional requirements for each category: $\mathrm{H}(14 \% \mathrm{CP}, 26.7 \% \mathrm{ADF}$, and $47 \%$ $\mathrm{NDF}$ ) and lactating Holstein cows (18\% CP, $21.2 \%$ $\mathrm{ADF}$, and $34.4 \% \mathrm{NDF}$ ) weighing $650 \mathrm{~kg}$ and producing $45 \mathrm{~kg}$ of $3.5 \% \mathrm{FCM}$ when consuming $26 \mathrm{~kg}$ of DM/d (NRC, 2001). Within each farm, diets were comprised of similar ingredients in similar proportions. Briefly, the main ingredients were corn silage and Tifton hay as forage and a corn, soybean, and cottonseed meal-based concentrate.

\section{Experimental Design}

During the summer and the winter, nulliparous $\mathrm{H}$ (n $=36$ and 34 , respectively), PL cows $(\mathrm{n}=37$ and 32 , respectively), and $\mathrm{RB}$ cows ( $\mathrm{n}=36$ and 31 , respectively) started a protocol to synchronize follicular wave emergence. On random days of the estrous cycle (d 0), cattle were treated with $2 \mathrm{mg}$ of estradiol benzoate (Sincrodiol, OuroFino, Cravinhos, SP, Brazil), $50 \mathrm{mg}$ of progesterone (OuroFino) and $150 \mu \mathrm{g}$ of d-cloprostenol (Sincrocio, OuroFino, Cravinhos, Brazil) i.m. plus a norgestomet ear implant (Crestar, Intervet, Cotia, SP, Brazil). On d 5, the implant was removed and ovum retrieval was performed ( 1 to $2 \mathrm{~d}$ following the expected new follicular wave emergence). This protocol was previously tested in $\mathrm{H}$ and lactating and nonlactating cows to ensure that the time of follicular wave emergence was similar in all groups without the need for protocol modifications (Ferreira et al., 2009). Previously tested semen from a single collection of a Holstein bull was used for in vitro embryo production (IVP). Oocytes obtained from ovaries collected in a single commercial abattoir, mainly from $B$. indicus beef cows, were simultaneously subjected to IVP as a quality control. Three replicates were done in each season (summer and winter). In each replicate (2 in farm A and 1 in farm B), 12 to14 animals of each group were subjected to ovum retrieval, and 100 to 233 oocytes derived from ovaries from the abattoir were used as quality control. When contamination was detected during the IVP, data was excluded from the study.

\section{Ultrasonographic Examinations}

Prior to each ovum retrieval session, both ovaries were examined by transrectal ultrasonography using a portable scanner (Aloka SSDV 500 with $5 \mathrm{MHz}$ convex array transducer housed in a plastic vaginal probe; Aloka, Tokyo, Japan). The total number of follicles in each ovary was recorded.

\section{Ovum Retrieval}

All $\mathrm{H}$ and cows were subjected to ovum retrieval on d 5 after synchronization. Cattle were contained in a chute for the oocyte collection procedure and an epidural anesthesia was administered with lidocaine hydrochloride 2\% (Anestésico L, Eurofarma, São Paulo, SP, Brazil) to facilitate the handling of the ovaries through the rectum. The perineal area was cleaned using water and alcohol prior to each session. All follicles $\geq 2 \mathrm{~mm}$ were aspirated using the portable scanner with a $5-\mathrm{MHz}$ convex array transducer housed in a plastic vaginal probe with a stainless steel needle guide connected to aspiration equipment and a vacuum system. Follicular aspirates were recovered via a $1.1-\mathrm{mm}$ i.d. by a $120-\mathrm{cm}$ length circuit (Watanabe Tecnologia Aplicada, Cravinhos, SP, Brazil), directly connected to a disposable $1.7 \mathrm{~mm} \times 48$ 
mm 16-gauge catheter (BD Angiocath, São Paulo, SP, Brazil) and a $50-\mathrm{mL}$ conical tube containing $15 \mathrm{~mL}$ of Dulbecco PBS (DPBS; Nutricell Nutrientes Celulares, Campinas, SP, Brazil) supplemented with $1 \%$ (vol/vol) fetal calf serum (FCS; Gibco Life Technologies, Grand Island, NY) and 5,000 IU/mL sodium heparin (Parinex, Hipolabor, Belo Horizonte, MG, Brazil) at 35 to $37^{\circ} \mathrm{C}$. The vacuum connected to the needle was set at 85 to $90 \mathrm{~mm} \mathrm{Hg}$. All retrieval procedures were performed by the same veterinarian.

The conical tube containing follicular aspirate was transported to a field laboratory and cumulus-oocyte complexes (COC) were washed using a $75-\mu \mathrm{m}$ filter (Watanabe Tecnologia Aplicada) and DPBS supplemented with $1 \%$ FCS. The COC were harvested, washed once in DPBS supplemented with $1 \% \mathrm{FCS}$ at $37^{\circ} \mathrm{C}$ and morphologically evaluated under a stereomicroscope (8-20 × magnification). The COC were morphologically classified based upon oocyte cytoplasm characteristics and the number of cumulus cell layers as viable or unviable. Compact COC with more than 3 layers of cumulus cells and oocytes with homogeneous cytoplasm, compact COC with $\leq 3$ layers of cumulus cells and oocytes with slightly heterogeneous cytoplasm, and COC partially denuded and oocytes with heterogeneous cytoplasm were considered viable for IVP and used in the study. Denuded or degenerated oocytes, oocytes with no cumulus cells over most of the zona pellucida surface or vacuolated and shrunken cytoplasm, and COC with expanded cumulus cells were considered as unviable for IVP (Wright, 1998) and excluded from the study. Viable COC were transported to the IVP laboratory in 1.5-mL cryotubes containing HEPES-buffered tissue culture medium 199 (TCM-199; Gibco Life Technologies, Grand Island, NY), 10\% FCS, $49.4 \mathrm{mg} /$ $\mathrm{mL}$ of sodium pyruvate (Sigma-Aldrich Chemical Co.; St. Louis, MO), and $50 \mathrm{mg}$ of gentamycin/mL at 37 to $39^{\circ} \mathrm{C}$.

\section{In Vitro Embryo Production}

The IVP was performed as described by Ferreira et al. (2010a). Prior to in vitro maturation, COC were washed 3 times in HEPES-buffered TCM-199, supplemented with $10 \%$ FCS and $50 \mu \mathrm{g}$ of gentamycin/ $\mathrm{mL}$, and once in maturation medium, composed of bicarbonate-buffered TCM-199 (Gibco Life Technologies) supplemented with $10 \% \mathrm{FCS}, 50 \mu \mathrm{g} / \mathrm{mL}$ of $\mathrm{LH}$ (Ayerst, Rouses Point, NY), $5 \mu \mathrm{g} / \mathrm{mL}$ of FSH (Folltropin, Vetrepharm, Belleville, ON, Canada), $0.1 \mu \mathrm{g} /$ $\mathrm{mL}$ of estradiol (Estradiol 17 $\beta$; Sigma-Aldrich Chemical Co.), $22 \mu \mathrm{g}$ of sodium pyruvate $/ \mathrm{mL}$, and $50 \mu \mathrm{g}$ of gentamycin $/ \mathrm{mL}$. The COC of each cow were separately cultured for $24 \mathrm{~h}$ in $70-\mu \mathrm{L}$ drops of maturation medium under mineral oil (D'Altomare, São Paulo, SP, Brazil) at $39^{\circ} \mathrm{C}$ in an atmosphere of $5 \% \mathrm{CO}_{2}$ in humidified air. After maturation, the COC were washed and subjected to in vitro fertilization (IVF) in $70-\mu \mathrm{L}$ drops of IVF medium under mineral oil. The IVF medium was Tyrode albumin lactate pyruvate (TALP; Bavister and Yanagimachi, 1977) supplemented with heparin (10 $\mu \mathrm{g} / \mathrm{mL})$, sodium pyruvate $(22 \mu \mathrm{g} / \mathrm{mL})$, gentamycin $(50$ $\mu \mathrm{g} / \mathrm{mL})$, fatty acid-free BSA $(6 \mathrm{mg} / \mathrm{mL})$, and PHE solution (2 $\mu M$ penicillin, $1 \mu M$ hypotaurine, and 0.25 $\mu M$ epinephrine).

A single ejaculate of frozen-thawed semen from a bull of known fertility was used. For IVF, straws were thawed for $30 \mathrm{~s}$ in a $35^{\circ} \mathrm{C}$ water bath. Semen was deposited on a 90 to $45 \%$ Percoll gradient prepared with sperm wash medium (modified Tyrode medium) and centrifuged at $320 \times g$ for $30 \mathrm{~min}$ to separate the mobile sperm and to remove the diluents and the seminal plasma. Afterward, the sperm pellet was evaluated for motility and concentration. Each fertilization drop received $5 \mu \mathrm{L}$ of sperm, to achieve a final concentration of $1 \times 10^{6}$ live sperm/ $\mathrm{mL}$. Sperm and $\mathrm{COC}$ were incubated at $38.5^{\circ} \mathrm{C}$ in an atmosphere of $5 \% \mathrm{CO}_{2}$ in humidified air for 18 to $20 \mathrm{~h}$.

Approximately $18 \mathrm{~h}$ after insemination, presumptive zygotes were stripped of cumulus cells by mechanical pipetting in TALP medium. Groups of presumptive zygotes were cocultured on a monolayer of cumulus cells that had attached to the surface plate during in vitro maturation (IVM). Thus, the IVM medium was gently changed to $50 \mu \mathrm{L}$ of CR2aa medium (Watanabe et al., 1999) supplemented with $2 \%$ FCS and $30 \mathrm{mg}$ of $\mathrm{BSA} / \mathrm{mL}$ to be used for embryo culture at $39^{\circ} \mathrm{C}$ in an atmosphere of $5 \% \mathrm{CO}_{2}$ in humidified air for 48 to $72 \mathrm{~h}$, when $30 \mu \mathrm{L}$ of fresh culture medium was added (first feeding). The proportion of cleaved oocytes was recorded on d 3 of embryo culture. The second feeding was done on d 6 of culture, the blastocyst rate (total number of blastocysts divided by total number of viable oocytes) was recorded on $\mathrm{d} 7$, and the hatching rate (number of hatched blastocysts divided by the number of blastocysts) was recorded on d 8 of embryo culture. Embryos were classified according to International Embryo Transfer Society (IETS) criteria (Wright 1998). Oocyte competence was assessed by the ability of the female gamete to produce a viable blastocyst. In turn, blastocyst viability was assessed by embryo morphology (i.e., clear blastocoel and a well-defined inner cell mass), blastocyst hatching rate, blastocyst cell number, and blastocyst DNA fragmentation rate.

\section{Terminal Deoxynucleotidyl Transferase-Mediated Deoxyuridine Triphosphate Nick End Labeling}

All blastocysts produced $(\mathrm{n}=229)$ were separated in groups according to the animal grouping and sea- 
son of the year, and analyzed to assess the rate of nuclear fragmentation. Every terminal deoxynucleotidyl transferase-mediated deoxyuridine triphosphate $(\mathrm{dUTP})$ nick end labeling $($ TUNEL) replicate $(\mathrm{n}=9)$ was run with blastocysts of the 3 groups of cattle, and extra blastocysts were used as positive and negative controls. Blastocysts were removed from the culture medium and washed 4 times in $100-\mu \mathrm{L}$ drops of PBS (pH 7.4) containing $0.1 \%$ polyvinyl-pyrrolidone (PVP) by transferring the embryos from drop to drop. The zona pellucida-intact embryos were fixed in a $400-\mu \mathrm{L}$ drop of $4 \%$ (wt/vol) paraformaldehyde in PBS-PVP ( $\mathrm{pH}$ 7.4) for $1 \mathrm{~h}$ at room temperature and then stored in the same solution at $4^{\circ} \mathrm{C}$ until assayed.

A commercial kit (TUNEL; Roche Molecular Biochemicals, Mannheim, Germany) was used to assess DNA fragmentation, according to the manufacturer's protocol. Briefly, embryos were washed 3 times in PBS-PVP and then permeabilized with $0.5 \%$ (vol/vol) Triton X-100 (Sigma-Aldrich Chemical Co.) in PBSPVP containing $0.1 \%$ (wt/vol) sodium citrate for $1 \mathrm{~h}$ at room temperature. Embryos were washed twice with PBS-PVP before labeling. Positive control embryos were incubated in $50 \mathrm{U}$ of RNase-free DNase $/ \mathrm{mL}$ for $1 \mathrm{~h}$ at $37^{\circ} \mathrm{C}$ in a humidified chamber and then washed twice with PBS-PVP before labeling. Negative control embryos and tested embryos were kept in PBS-PVP drops under the same conditions.

Embryos were placed in $10-\mu \mathrm{L}$ drops of fluorescein isothiocyanate-conjugated dUTP plus the enzyme terminal deoxynucleotidyl transferase, and incubated in the dark for $1 \mathrm{~h}$ at $37^{\circ} \mathrm{C}$ in a humidified chamber. Then, embryos were washed 3 times with PBS-PVP. Negative controls were incubated in the absence of the enzyme. The total number of nuclei was obtained by labeling in $10 \mu \mathrm{g} / \mathrm{mL}$ of Hoechst 33342 (Invitrogen, Carlsbad, $\mathrm{CA})$ diluted in PBS for $10 \mathrm{~min}$ in the dark. After washing twice in PBS-PVP, embryos were mounted onto slides with coverslips using VectaShield Mounting Medium (Vector Laboratories Inc., Burlingame, CA). The TUNEL-labeled nuclei and total number of nuclei were counted using a fluorescence microscope with a dual filter (Axioplan; Carl Zeiss, Hallbergmoos, Germany) and the AxioVs40 software (V4.6.1.0; Carl Zeiss). The TUNEL-labeled nuclei were visualized at $579-\mathrm{nm}$ excitation and 599-nm emission, whereas Hoechst-labeled nuclei were evaluated at $350 \mathrm{~nm}$ and $450 \mathrm{~nm}$, respectively.

Nuclear fragmentation was determined as the percentage of TUNEL-labeled nuclei to the total cell number. Each embryo of each cow or $\mathrm{H}$ was individually examined in each season (winter and summer). Positive controls had all blastomeres labeled, whereas negative controls had no TUNEL labeling.

\section{Statistical Analysis}

Tests for normality of residuals and homogeneity of variances were conducted for each variable. Data that did not fulfill the assumptions for ANOVA were transformed accordingly. Continuous data (i.e., respiration rate, rectal temperature, cutaneous temperature, number of oocytes, number of viable oocytes, and total number of nuclei, rates of cleavage, blastocyst and hatched blastocyst formation, and DNA fragmentation) were analyzed by ANOVA using the GLIMMIX procedure of SAS version 9.2 (SAS/STAT, SAS Institute Inc., Cary, $\mathrm{NC)}$ for normal distribution.

The explanatory variables considered for inclusion in the models were group, farm, season (winter vs. summer), DIM, number of previous inseminations, BCS, and interactions. The final logistic regression model removed variables by a backward elimination based on the Wald statistics criterion when $P>0.20$. The variables that were included in the final model were group, season (winter vs. summer), number of previous inseminations, and BCS.

Environmental measures were analyzed by ANOVA using the GLIMMIX procedure of SAS. The explanatory variables considered for inclusion in the models were year, month, farm, and interaction between variables. Significance was considered at $P<0.05$. Values are presented as means \pm SEM.

\section{RESULTS}

No effect of interaction $(P>0.05)$ was found for any analyzed variable either between farms and groups, or between replicates and groups. The maximum and minimum environmental temperatures during March (summer) were $39.1 \pm 0.2$ and $18.5 \pm 0.2^{\circ} \mathrm{C}$ in farm $\mathrm{A}$, and, $35.0 \pm 0.2$ and $17.0 \pm 0.2^{\circ} \mathrm{C}$ in farm B. In August (winter) they were $28.9 \pm 0.2$ and $14.4 \pm 0.2^{\circ} \mathrm{C}$ in farm $\mathrm{A}$, and, $30.0 \pm 0.2$ and $10.0 \pm 0.2^{\circ} \mathrm{C}$ in farm B. The relative air humidity was $61 \pm 0.01$ (farm A) and $62 \pm 0.01$ (farm B) versus $53.9 \pm 0.01$ (farm A) and $53.8 \pm 0.01 \%$ (farm B) during the summer and winter, respectively. As for physiological traits, H, PL, and RB cows had similar $(P=0.17)$ respiration rates during the winter, but PL and RB cows had an increased respiration rate during the summer compared with the same groups during the winter $(P<0.0001)$ and with $\mathrm{H}$ during the summer $(P<0.0001$; Figure $2)$. The $\mathrm{H}$ maintained similar rectal temperature during summer and winter $(P=0.73)$, whereas PL and $\mathrm{RB}$ cows had elevated rectal temperatures during the summer compared with the same groups during the winter $(P<0.0001)$ and with $\mathrm{H}$ during the summer $(P$ $<0.0001$; Figure 3$)$. As for cutaneous temperature, an 


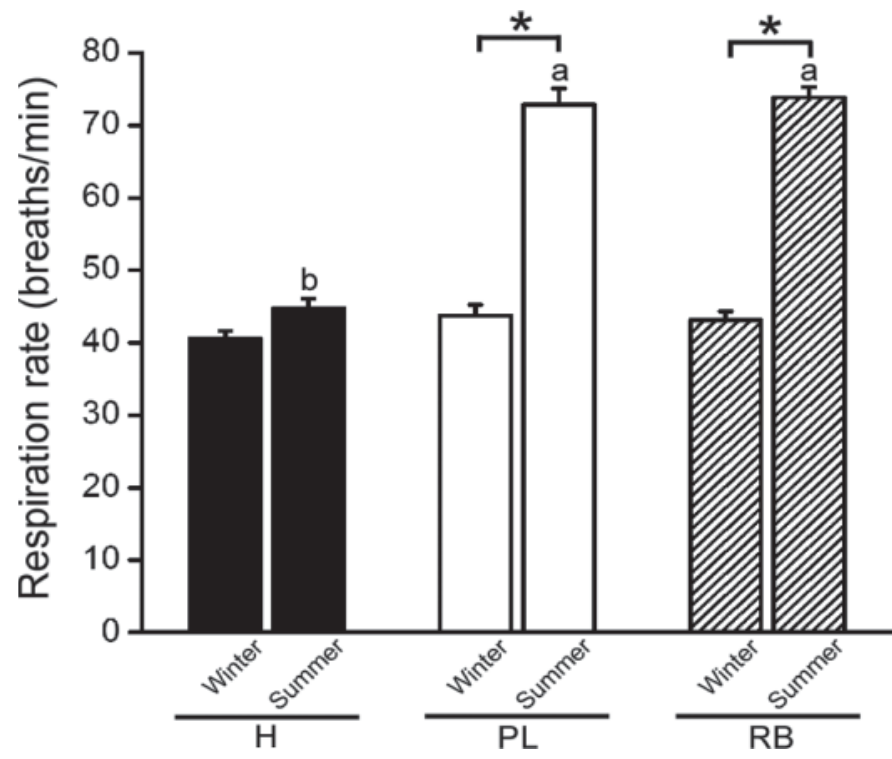

Figure 2. Respiration rate (breaths/min) of Holstein cattle of different groups during summer and winter heifers $(\mathrm{H} ; \mathrm{n}=36$ and 34 respectively), high-producing cows in peak lactation (PL; $\mathrm{n}=37$ and 32 , respectively), and repeat-breeder cows (RB; $\mathrm{n}=36$ and 31 , respectively)]. Interaction season-group $(P<0.0001)$; mean $( \pm \mathrm{SEM})$ values within season $(\mathrm{a} \neq \mathrm{b})$ and within group $(*)$ differ $(P<0.0001)$.

interaction between season and group $(P=0.05$; Figure $4)$ was detected. All groups had increased $(P<0.0001)$ cutaneous temperature during the summer; however, it was always lower $(P<0.001)$ in $\mathrm{H}$ than cows, regard- less of season. Summarizing, during the summer the physiological measures of PL and RB cows were more affected in relation to $\mathrm{H}$.

The effects of these physiological alterations on oocyte quality were investigated. At ovum retrieval, $\mathrm{H}$ and cows provided a similar $(P=0.07)$ number of recovered oocytes and viable oocytes during the winter. Nonetheless, during the summer, oocyte numbers were decreased $(P<0.0001)$ in cows (Table 1$)$. A quality control system was established based on abattoir-derived beef cattle oocytes to test reliability of the IVP routine. Developmental rates of the abattoir-derived oocytes were as follows: $80.7 \% \pm 1.5$ versus $73.7 \% \pm$ $1.7(P=0.003)$ cleavage, $45.4 \% \pm 1.9$ versus $39.0 \%$ $\pm 2.9(P=0.06)$ blastocyst, and $36.4 \% \pm 4.0$ versus $44.7 \% \pm 6.4(P=0.3)$ hatched during the summer $(\mathrm{n}=582)$ and winter $(\mathrm{n}=453)$, respectively. As for the ovum retrieval-derived oocytes, cleavage rates were similar between animal groups $[\mathrm{H}=51.7 \% \pm 4.5$ (n $=375), \mathrm{PL}=37.9 \% \pm 5.1(\mathrm{n}=390), \mathrm{RB}=41.9 \% \pm$ $4.5(\mathrm{n}=666) ; P=0.20]$ and seasons $[$ winter $=42.3 \%$ $\pm 3.4(\mathrm{n}=979)$, summer $=45.8 \% \pm 4.4(\mathrm{n}=452) ; P$ $=0.50]$. Yet, when blastocyst rates were evaluated, an interaction between group and season $(P<0.0001)$ was found (Figure 5), indicating that the effect of season was dependent on group, unlike the rate of cleavage. Regardless of season, RB cow blastocyst rates were lower $(P<0.0001)$ than for $\mathrm{H}$. In the summer, RB blastocyst rate dropped $(P<0.002)$ in comparison to

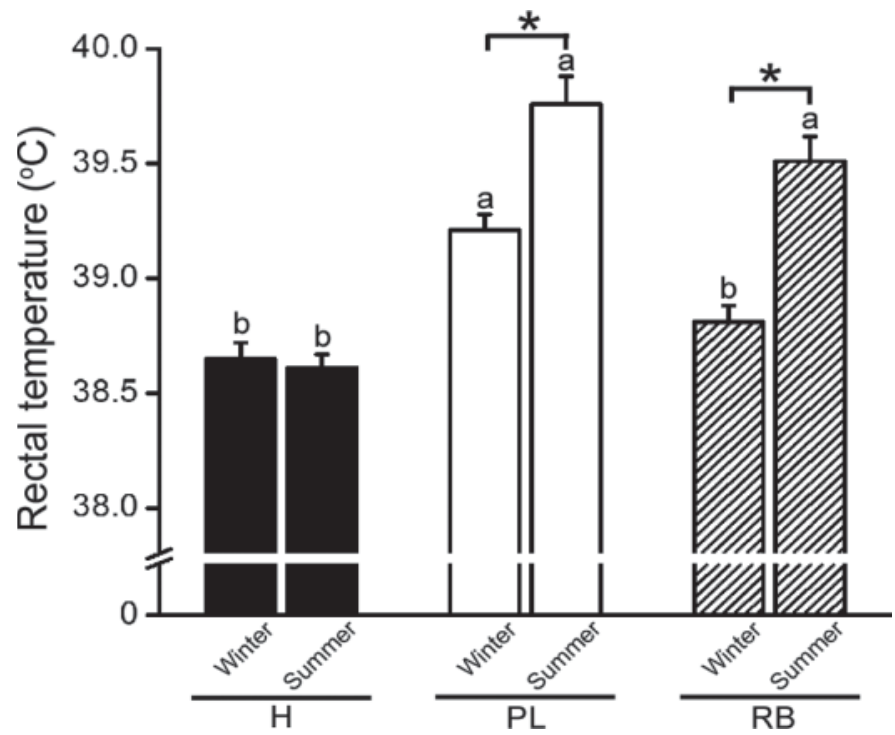

Figure 3. Rectal temperature $\left({ }^{\circ} \mathrm{C}\right)$ of Holstein cattle of different groups during summer and winter [heifers $(\mathrm{H} ; \mathrm{n}=36$ and 34 , respectively), high-producing cows in peak lactation (PL; $\mathrm{n}=37$ and 32 , respectively), and repeat-breeder cows (RB; $\mathrm{n}=36$ and 31 , respectively)]. Interaction season-group $(P<0.0001)$; mean $( \pm$ SEM $)$ values within season $(\mathrm{a} \neq \mathrm{b})$ and within group $(*)$ differ $(P<0.0001)$.

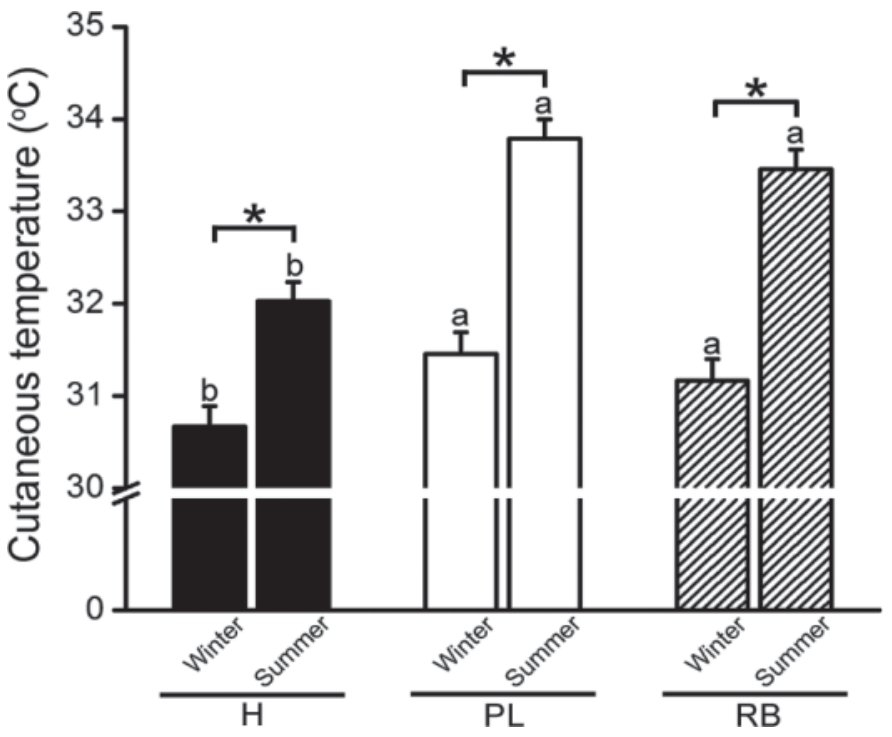

Figure 4. Cutaneous temperature $\left({ }^{\circ} \mathrm{C}\right)$ of Holstein cattle of different groups during summer and winter heifers $(\mathrm{H} ; \mathrm{n}=36$ and 34 , respectively), high-producing cows in peak lactation (PL; $\mathrm{n}=37$ and 32 , respectively), and repeat-breeder cows (RB; $\mathrm{n}=36$ and 31 , respectively)]. Interaction season-group $(P=0.05)$; mean ( \pm SEM) values within season $(\mathrm{a} \neq \mathrm{b})$ and within group $(*)$ differ $(P<0.0001)$. 
winter, becoming lower than for PL cows $(P<0.001)$. Regarding the blastocyst hatched rate, no interaction was found among animal groups and seasons $(P=0.3)$, which enabled grouping of data. The overall hatching rate was similar among groups $(19.3 \%, \mathrm{n}=288 ; P=$ $0.2)$, regardless of season. However, it was decreased during the summer $(23.0 \%, \mathrm{n}=218$ vs. $6.5 \%, \mathrm{n}=70$; $P=0.03$ ), regardless of category. In agreement with the blastocyst rate, RB blastocyst quality was compromised in comparison to $\mathrm{H}$ and $\mathrm{PL}$ during the summer $(P=0.01)$, but not during the winter $(P=0.3)$, as indicated by the percentage of TUNEL-positive cells (Figure 6). Regarding the number of nuclei in blastocysts, no interaction between group and season $(P=$ 0.80 ) was found; thus, data were grouped. Regardless of season, $\mathrm{H}$ had increased nuclei numbers $(\mathrm{H}=253.0$ \pm 12.2 , which were greater than both $\mathrm{PL}=202.5 \pm$ 9.9 and $\mathrm{RB}=207.0 \pm 8.3 ; P=0.001$ ), whereas during the summer the number of nuclei was decreased $(230.6 \pm 6.8$ vs. $175.0 \pm 9.0 ; P=0.0005)$, regardless of group. Summarizing, a pronounced effect of summer was observed in RB oocyte competence to develop into blastocysts in comparison to $\mathrm{H}$ and PL.

\section{DISCUSSION}

Given that repeat breeding is a multifactorial problem involving several extrinsic and intrinsic factors coupled to the individual animal, an experiment based on ovum retrieval-derived oocytes allows the study of effects exerted on the gamete until the time it is recovered from the donor. In this context, our work focuses on examining oocytes harvested from Holstein cattle of 3 groups (H, PL, and RB) by ovum retrieval to assess oocyte recovery and competence to develop into viable blastocysts. Environmental conditions were considered by harvesting oocytes from all groups during winter and summer.

When oocytes were retrieved from RB cows during the summer, their quality was severely compromised, showing a rate of blastocyst development decreased by almost half in comparison to non-RB cows (PL) or almost one-third in comparison to $\mathrm{H}$. This loss of competence was confirmed by a higher rate of nuclear fragmentation (TUNEL-positive cells), indicating that blastocysts from RB cows produced from oocytes retrieved during the summer have lower capability to undergo implantation and develop to term (Fabian et al., 2005; El-Sayed et al., 2006). On the other hand, the effect of RB cows on oocyte quality was not as evident when assessed during the winter. In this season, although the embryonic developmental rates of RB-derived oocytes were lower in comparison to those derived from $\mathrm{H}$, they were similar to non-RB cows (PL). The

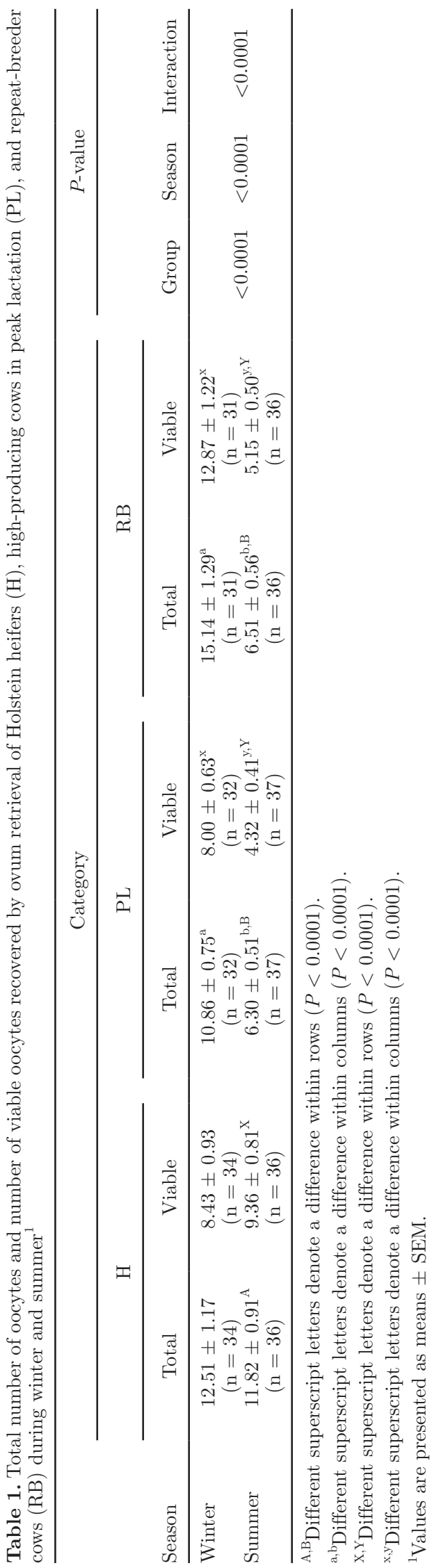

Journal of Dairy Science Vol. 94 No. 5, 2011 


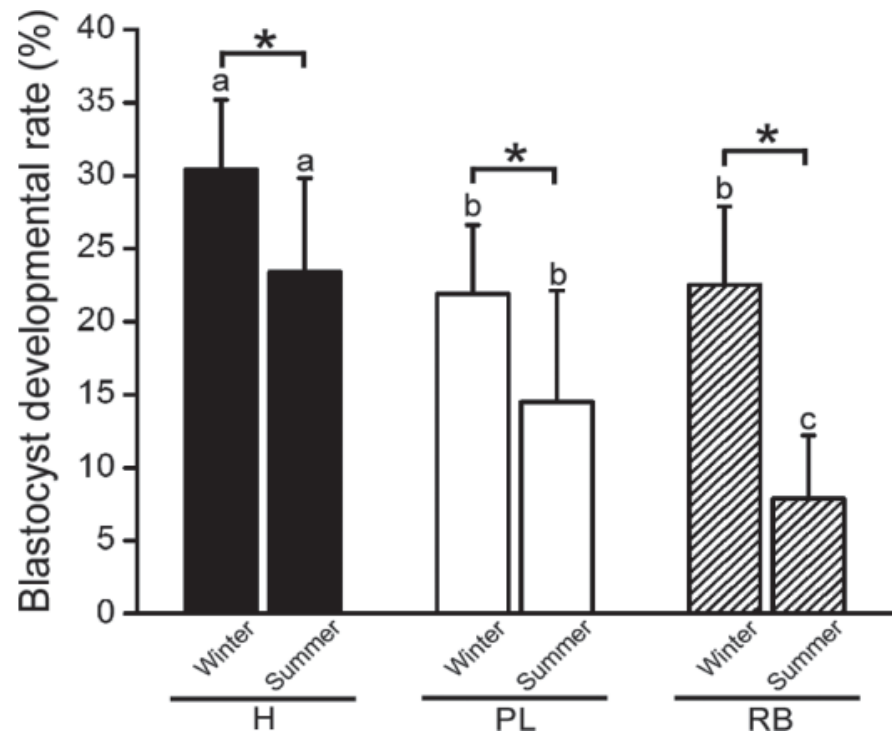

Figure 5. Blastocyst rate $7 \mathrm{~d}$ post-in vitro insemination of Holstein cattle oocytes of different groups during summer and winter [heifers $(\mathrm{H} ; \mathrm{n}=150$ and 244 , respectively), high-producing cows in peak lactation (PL; $\mathrm{n}=103$ and 191, respectively), and repeat-breeder cows $(\mathrm{RB} ; \mathrm{n}=177$ and 413 , respectively)]. Interaction season-group $(P<$ $0.0001)$; mean $( \pm$ SEM) values within season $(\mathrm{a} \neq \mathrm{b} \neq \mathrm{c})$ and within group $\left(^{*}\right)$ differ $(P<0.0001)$.

same result was found for nuclear fragmentation rate, indicating a higher susceptibility of RB oocytes to the effects exerted by summer HS on the female gamete.

Oocyte quality appears compromised in PL cows, whereas similarities on embryonic developmental rates found between PL and RB during the winter of the present study may be sufficient to suggest a lack of quality in RB gametes. For instance, metabolic changes in preantral follicles, follicular fluid, and dominant follicles affecting the quality of both oocyte and granulosa cells were described in dairy cows with negative energy balance during the early postpartum period (Britt, 1994; Leroy et al., 2004). On the other hand, even with their cutaneous temperature increased during the summer, $\mathrm{H}$ were capable of keeping similar respiration rate and rectal temperature during the winter and summer, whereas cows have these 3 measures increased during the summer, as seen in our study.

It is known that a classical physiological response to increased body temperature is redistribution of blood to the skin (Choshniak et al., 1982). Blood flow changes in response to HS within minutes (Kamijo et al., 2005) with the aim of increasing the heat loss from the skin. Increased blood flow to the periphery associated with thermoregulation concurrently decreased blood flow to the internal organs, including the reproductive tract (i.e., uterus, ovaries, cervix, and oviduct; Roman-Ponce et al., 1978; Lublin and Wolfenson, 1996). Thus, increased cutaneous temperature reflects HS and it is probably a consequence of the redistribution of blood flow to the skin aiming for thermoregulation. The $\mathrm{H}$ are probably more efficient at thermoregulation than cows, as reflected by rectal temperature. Yet, possible decreased vascular perfusion of the preovulatory follicle, as a result of blood flow redistribution during HS, may have compromised oocyte function, as shown by embryonic developmental rate following IVP. According to Sartori et al. (2002), lactating cows have greater increase in body temperature than do $\mathrm{H}$ in response to an increase in environmental temperature. These different responses to summer are probably due to decreased thermoregulatory ability of lactating cows, which may be related to the high metabolic energy associated with milk production (Berman et al., 1985). Therefore, greater developmental rates for $\mathrm{H}$ compared with $\mathrm{RB}$ cows were expected.

A point to be considered in our study is the in vitro condition evaluated and the way the data were obtained may not be extrapolated to what is seen in vivo. Although a system based on ovum retrieval-derived oocytes and in vitro fertilization allowed assessment of the effect accumulated on the gamete through folliculogenesis, it prevents the study of an interaction between the gamete and the animal Although we have assessed blastocyst quality by the rate of nuclear fragmentation

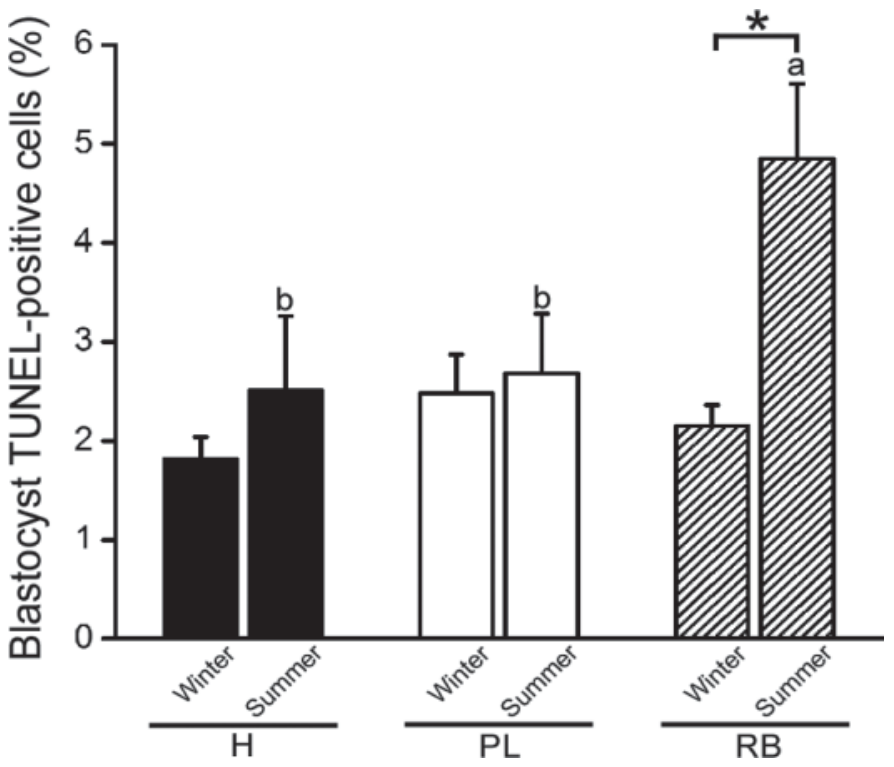

Figure 6. Blastocyst terminal deoxynucleotidyl transferase-mediated deoxyuridine triphosphate (dUTP) nick end labeling (TUNEL)positive cells $7 \mathrm{~d}$ post-in vitro insemination of Holstein oocytes of different groups during summer and winter heifers $(\mathrm{H} ; \mathrm{n}=13$ and 61 , respectively), high-producing cows in peak lactation (PL; $\mathrm{n}=14$ and 49 , respectively), and repeat-breeder cows ( $\mathrm{n}=14$ and 78 , respectively)]. Interaction season-group $(P<0.01)$; mean $( \pm$ SEM $)$ values within season $(\mathrm{a} \neq \mathrm{b})$ and within group $\left({ }^{*}\right)$ differ $(P<0.01$ and $P<$ 0.001 , respectively). 
and total cell number, embryo transfer to recipient cows and analysis of development to term would be the best way to check blastocyst viability. In the present study, similar cleavage rates were achieved by cows (PL and $\mathrm{RB}$ ) and $\mathrm{H}$ in both periods. Blastocysts had 230 nuclei during winter, but only 175 during summer. In respect to the effect of summer on oocyte quality, it was shown that HS during folliculogenesis has the potential to compromise the oocyte, either because of direct actions of elevated temperature on it or because of alterations in follicular function compromising oocyte quality (Hansen and Arechiga, 1999). In vivo (de S. Torres-Júnior et al., 2008) and in vitro (Barros et al., 2006; Gendelman et al., 2010) studies demonstrated that elevated temperatures do not affect oocyte cleavage rate after fertilization. These data suggest that the in vitro fertilization rate is similar among groups and it is not critically affected by the season. Yet, Gendelman et al. (2010) suggested a deleterious seasonal effect on multiparous Holstein cow oocyte developmental competence with delayed cleavage, leading to lower blastocyst rate, although similar cleavage rates were observed. Accordingly, in the present study, blastocyst rates were decreased during the summer. Blastocyst hatching rate and total blastocyst cell number were decreased during the summer in all groups, indicating a critical effect on oocyte quality expressed later during development. A detrimental effect of summer on blastocyst rate, quality, or cell number supports scientific studies showing decreased in vitro or in vivo embryonic development under conditions of HS (Hansen et al., 2001; Rivera and Hansen, 2001; Al-Katanani et al., 2002). The exact mechanisms by which HS compromises the oocyte are not known.

Interestingly, RB cows were the animals most affected during summer, showing a decrease in blastocyst rate and viability. Thus, an association of factors regarding the effect of summer on the oocyte and peculiarities of $\mathrm{RB}$ cows may be related to decreased fertility in this group of cows. Several authors reported that delayed embryonic development may be a common factor for most RB heifers (Gustafsson, 1985; Gustafsson and Plöen, 1986). It is difficult to make generalizations regarding predominant causes of repeat breeding. Several endogenous factors acting at different levels (i.e., ovary, oviduct, and uterus) may affect oocyte and embryo quality, determining the incidence of repeat breeding in dairy cows. Such factors can be driven by exogenous stimuli such as HS. In the present study, summer HS potentially impaired RB oocyte developmental competence, resulting in decreased quality blastocysts (high fragmentation rate). Besides, retarded cleavage timing, consequential of HS, may explain the low hatching rate of these blastocysts. Altogether, fertility problems asso- ciated with repeat breeding are maximized by summer HS and certainly involve oocyte quality disruption.

\section{CONCLUSIONS}

Heat stress negatively affected the physiological measures and the IVP in RB Holstein cows. Although the cleavage rate was similar to that of other groups (PL and $\mathrm{H}$ ), the blastocyst rate of $\mathrm{RB}$ cows was severely compromised by HS. The fragmentation rate of RB blastocysts was increased during the summer compared with winter and other groups, suggesting that the association of RB fertility problems and summer HS may potentially impair oocyte quality. Our findings provide evidence of a greater sensitivity of RB oocytes to summer HS.

\section{ACKNOWLEDGMENTS}

We acknowledge the financial support from Fundação de Amparo à Pesquisa do Estado de São Paulo (FAPESP; Proc.2009/00938-3) and Coordenação de Aperfeiçoamento de Pessoal de Nível Superior (CAPES); the hormone donation from OUROFINO Saúde Animal (São Paulo, Brazil); the cooperation and assistance of Vitrogen (Cravinhos, SP, Brazil) and Vida Reprodutiva (Cravinhos, SP, Brazil) companies; and the farms Santa Rita (Descalvado, SP, Brazil) and Campestre (São Pedro, SP, Brazil) for supplying the animals and management necessary to conduct this study.

\section{REFERENCES}

Al-Katanani, Y. M., F. F. Paula-Lopes, and P. J. Hansen. 2002. Effect of season and exposure to heat stress on oocyte competence in Holstein cows. J. Dairy Sci. 85:390-396.

Ambrose, J. D., M. Drost, R. L. Monson, J. J. Rutledge, M. L. Leibfried-Rutledge, M.-J. Thatcher, T. Kassa, M. Binelli, P. J. Hansen, P. J. Chenoweth, and W. W. Thatcher. 1999. Efficacy of timed embryo transfer with fresh and frozen in vitro produced embryos to increase pregnancy rates in heat-stressed dairy cattle. J. Dairy Sci. 82:2369-2376.

Badinga, L., W. W. Thatcher, T. Diaz, M. Drost, and D. Wolfenson. 1993. Effect of environmental heat stress on follicular development and steroidogenesis in lactating Holstein cows. Theriogenology 39:797-810.

Båge, R., S. Petyim, B. Larsson, T. Hallap, A.-S. Bergqvist, H. Gustafsson, and H. Rodríguez-Martínez. 2003. Oocyte competence in repeat-breeder heifers: Effects of an optimized ovum pick-up schedule on expression of oestrus, follicular development and fertility. Reprod. Fertil. Dev. 15:115-123.

Barros, C. M., M. F. Pegorer, J. L. M. Vasconcelos, B. G. Eberhardt, and F. M. Monteiro. 2006. Importance of sperm genotype (indicus versus taurus) for fertility and embryonic development at elevated temperatures. Theriogenology 65:210-218.

Baruselli, P. S., R. M. Ferreira, M. F. Sa, L. F. T. Nasser, C. A. Rodrigues, and G. A. Bo. 2010. Bovine embryo transfer recipient synchronisation and management in tropical environments. Reprod. Fertil. Dev. 22:67-74.

Bavister, B. D., and R. Yanagimachi. 1977. The effects of sperm extracts and energy sources on the motility and acrosome reaction of hamster spermatozoa in vitro. Biol. Reprod. 16:228-237. 
Berman, A., Y. Folman, M. Kaim, M. Mamen, Z. Herz, D. Wolfenson, A. Arieli, and Y. Graber. 1985. Upper critical temperatures and forced ventilation effects for high-yielding dairy cows in a subtropical climate. J. Dairy Sci. 68:1488-1495.

Britt, J. H. 1994. Follicular development and fertility: Potential impacts of negative energy balance. In: Proc. Nat. Reprod. Symp. $103-12$

Choshniak, I., D. McEwan-Jenkinson, D. R. Blatchford, and M. Peaker. 1982. Blood flow and catecholamine concentration in bovine and caprine skin during thermal sweating. Comp. Biochem. Physiol. C 71C:37-42.

de S. Torres-Júnior, J. R. S., M. de F. A. Pires, W. F. de Sá, A. de M. Ferreira, J. H. M. Viana, L. S. A. Camargo, A. A. Ramos, I. M. Folhadella, J. Polisseni, C. de Freitas, C. A. A. Clemente, M. F. de Sá Filho, F. F. Paula-Lopes, and P. S. Baruselli. 2008. Effect of maternal heat-stress on follicular growth and oocyte competence in Bos indicus cattle. Theriogenology 69:155-166.

Edmonson, A. J., I. J. Lean, L. D. Weaver, T. Farver, and G. Webster. 1989. A body condition scoring chart for Holstein dairy cows. J. Dairy Sci. 72:68-78.

El-Sayed, A., M. Hoelker, F. Rings, D. Salilew, D. Jennen, E. Tholen, M.-A. Sirard, K. Schellander, and D. Tesfaye. 2006. Large-scale transcriptional analysis of bovine embryo biopsies in relation to pregnancy success after transfer to recipients. Physiol. Genomics $28: 84-96$

Fabian, D., J. Koppel, and P. Maddox-Hyttel. 2005. Apoptotic processes during mammalian preimplantation development. Theriogenology 64:221-231.

Ferreira, C. R., J. P. Burgstaller, F. Perecin, J. M. Garcia, M. R. Chiaratti, S. C. Méo, M. Müller, L. C. Smith, F. V. Meirelles, and R. Steinborn. 2010a. Pronounced segregation of donor mitochondria introduced by bovine ooplasmic transfer to the female germ-line. Biol. Reprod. 82:563-571.

Ferreira, R. M., H. Ayres, M. R. Chiaratti, C. A. Rodrigues, B. G. Freitas, F. V. Meirelles, and P. S. Baruselli. 2010b. Heat stress and embryo production in high-producing dairy cows. Acta Sci. Vet. 38:s277-s315.

Ferreira, R. M., H. Ayres, J. R. G. Maio, and P. S. Baruselli. 2009. Day of follicular wave emergence of Holstein heifers and cows submitted to protocols for synchronization of follicular wave emergence using or not injectable progesterone. Anim. Reprod. 6:259.

Gendelman, M., A. Aroyo, S. Yavin, and Z. Roth. 2010. Seasonal effects on gene expression, cleavage timing, and developmental competence of bovine preimplantation embryos. Reproduction 140:73-82.

Graden, A. P., D. Olds, C. R. Mochow, and L. R. Mutter. 1968. Causes of fertilization failure in repeat breeding cattle. J. Dairy Sci. $51: 778-781$.

Gustafsson, H. 1985. Characteristics of embryos from repeat breeder and virgin heifers. Theriogenology 23:487-498.

Gustafsson, H., and U. Emanuelson. 2002. Characterization of the repeat breeding syndrome in Swedish dairy cattle. Acta Vet. Scand. $43: 115-125$.

Gustafsson, H., and K. Larsson. 1985. Embryonic mortality in heifers after artificial insemination and embryo transfer: Differences between virgin and repeat breeder heifers. Res. Vet. Sci. 39:271274

Gustafsson, H., and L. Plöen. 1986. The morphology of 16 and 17 day old bovine blastocysts from virgin and repeat breeder heifers. Anat. Histol. Embryol. 15:277-287.

Hansen, P. J., and C. F. Aréchiga. 1999. Strategies for managing reproduction in the heat-stressed dairy cow. J. Anim. Sci. 77(Suppl. 2):36-50.

Hansen, P. J., M. Drost, R. M. Rivera, F. F. Paula-Lopes, Y. M. AlKatanani, C. E. Krininger III, and C. C. Chase Jr. 2001. Adverse impact of heat stress on embryo production: Causes and strategies for mitigation. Theriogenology 55:91-103.

Kamijo, Y.-I., K. Lee, and G. W. Mack. 2005. Active cutaneous vasodilation in resting humans during mild heat stress. J. Appl. Physiol. 98:829-837.

Leroy, J. L. M. R., T. Vanholder, J. R. Delanghe, G. Opsomer, A. Van Soom, P. E. J. Bols, J. Dewulf, and A. de Kruif. 2004. Metabolic changes in follicular fluid of the dominant follicle in high-yielding dairy cows early post partum. Theriogenology 62:1131-1143.

Lublin, A., and D. Wolfenson. 1996. Lactation and pregnancy effects on blood flow to mammary and reproductive systems in heat-stressed rabbits. Comp. Biochem. Physiol. A Physiol. 115:277-285.

NRC. 2001. Nutrient Requirements of Dairy Cattle. $7^{\text {th }}$ rev. ed. Natl Acad. Sci., Washington, DC.

Putney, D. J., M. Drost, and W. W. Thatcher. 1989. Influence of summer heat stress on pregnancy rates of lactating dairy cattle following embryo transfer or artificial insemination. Theriogenology $31: 765-778$.

Rivera, R. M., and P. J. Hansen. 2001. Development of cultured bovine embryos after exposure to high temperatures in the physiological range. Reproduction 121:107-115.

Rocha, A., R. D. Randel, J. R. Broussard, J. M. Lim, R. M. Blair J. D. Roussel, R. A. Godke, and W. Hansel. 1998. High environmental temperature and humidity decrease oocyte quality in Bos taurus but not in Bos indicus cows. Theriogenology 49:657-665.

Rodrigues, C. A., H. Ayres, R. M. Ferreira, A. A. Teixeira, R. F. Mancilha, M. E. F. Oliveira, A. H. Souza, and P. S. Baruselli. 2007. Comparison of pregnancy rates after artificial insemination or embryo transfer in high-producing repeat breeder Holstein cows. Acta Sci. Vet. 35:s1255.

Roman-Ponce, H., W. W. Thatcher, D. Caton, D. H. Barron, and C. J. Wilcox. 1978. Thermal stress effects on uterine blood flow in dairy cows. J. Anim. Sci. 46:175-180.

Roth, Z., A. Arav, A. Bor, Y. Zeron, R. Braw-Tal, and D. Wolfenson. 2001. Improvement of quality of oocytes collected in the autumn by enhanced removal of impaired follicles from previously heatstressed cows. Reproduction 122:737-744.

Sartori, R., J. M. Haughian, R. D. Shaver, G. J. Rosa, and M. C. Wiltbank. 2004. Comparison of ovarian function and circulating steroids in estrous cycles of Holstein heifers and lactating cows. J. Dairy Sci. 87:905-920.

Sartori, R., R. Sartor-Bergfelt, S. A. Mertens, J. N. Guenther, J. J. Parrish, and M. C. Wiltbank. 2002. Fertilization and early embryonic development in heifers and lactating cows in summer and lactating and dry cows in winter. J. Dairy Sci. 85:2803-2812.

Watanabe, Y. F., M. R. Watanabe, M. A. V. Galerani, R. A. Vila, and R. B. Lôbo. 1999. The influence of B2 and modified CR2 on the in vitro production of bovine with cumulus and oviduct co-culture. Theriogenology 51: 259 .

Wolfenson, D., Z. Roth, and R. Meidan. 2000. Impaired reproduction in heat-stressed cattle: Basic and applied aspects. Anim. Reprod. Sci. 60-61:535-547.

Wolfenson, D., W. W. Thatcher, L. Badinga, J. D. Savio, R. Meidan, B. J. Lew, R. Braw-Tal, and A. Berman. 1995. Effect of heat stress on follicular development during the estrous cycle in lactating dairy cattle. Biol. Reprod. 52:1106-1113.

Wright, J. 1998. Photomicrographic illustration of embryo codes. Pages 167-170 in Manual of the International Embryo Transfer Society. 3rd ed. D. A. Stringfellow and S. M. Seidel, ed. International Embryo Transfer Society, Savoy, IL.

Yusuf, M., T. Nakao, R. B. Ranasinghe, G. Gautam, S. T. Long, C. Yoshida, K. Koike, and A. Hayashi. 2010. Reproductive performance of repeat breeders in dairy herds. Theriogenology 73:1220 1229 . 